Instructions for authors, subscriptions and further details:

http://brac.hipatiapress.com

\title{
Tecnología y Creación Musical
}

Salvador Oriola Requena ${ }^{1}$

1) Facultad de Educación. Universidad de Barcelona (España)

Date of publication: June $3^{\text {rd }}, 2016$

Edition period: June 2016 - October 2016

To cite this article: Oriola Requena, S. (2016). Tecnología y Creación Musical. Lleida: Editorial Milenio. [Review of the book]. Barcelona, Research, Art, Creation, 4(2), 205-206. doi: 10.17583/brac.2016.1417

To link this article: http://dx.doi.org/10.17583/brac.2016.1417

\section{PLEASE SCROLL DOWN FOR ARTICLE}

The terms and conditions of use, except where otherwise noted, are related to the Open Journal System and to Creative Commons Attribution License (CCBY). The indication must be expressly stated when necessary. 
BRAC - Barcelona Research Art Creation. Vol. 4 No. 2, June 2016, pp. 205-206

(Received: 11 February 2015; Accepted: 20 March 2016; Published: 3 June 2016)

\section{Reviews (I)}

Aviñoa, X. (ed.), Brugarolas, O., Ferrer, E., Rossinyol, O., Tamarit, R. Gustems, J., Martínez, M. L., Carbonell, J., Berenguer, J. M., De la Torre, M. J., Calderón, D., Giné, E., Cascudo, T., Palacios, M., Calmell, C., Polo, M., Faccio, J. J. (2014). Tecnología y creación musical. Lleida: Editorial Milenio ISBN: 978-84-9743-655-7. Depósito Legal: L 1.551-2014

Desde la época de la revolución industrial se establece una íntima relación entre música y tecnología; todos conocemos la repercusión que han tenido y tienen descubrimientos como la música grabada, Internet o los dispositivos móviles en la difusión y acceso a cualquier tipo de música. En cambio, es mucho menos conocida la aportación que la tecnología ha tenido en un campo tan atractivo y fructífero como es la creatividad musical.

Con el amplio desarrollo tecnológico que se da a partir de la revolución industrial se abren nuevos planteamientos por lo que a la creación musical se refiere. Estos planteamientos, tal y como afirma el doctor Aviñoa (editor y coautor), se alejarán cada vez más de la excelencia como garantía de proximidad y se acercarán a lo novedoso como argumento.

El libro que presentamos consiste en un compendio de textos, escritos por especialistas pertenecientes a diferentes disciplinas, que pretenden analizar y dar a conocer la importancia que han tenido avances tecnológicos de distinta índole en los mecanismos de difusión, producción y creación musical durante los dos últimos siglos. 
Los diecisiete capítulos que componen el texto están organizados en torno a tres grandes apartados. Un primer apartado, de carácter más técnico, se dedica a exponer detalladamente la evolución mecánica y productiva, experimentada por diferentes tipologías de instrumentos como los instrumentos de cuerda percutida (piano, órgano, etc.) o los instrumentos escolares, entre otros, y de qué forma esta evolución ha repercutido tanto en el proceso de recepción como en el de creación musical.

El segundo apartado, de carácter más analítico, dedica sus capítulos a explicar la influencia de la tecnología en aspectos diversos como por ejemplo la utilización de la voz como instrumento musical, el proyecto "Sonidos en Causa" llevado a cabo por la orquesta del Caos, la evolución de estilo en los guitarristas de jazz, o la música grabada.

Finalmente, el texto concluye con un último apartado titulado "Música, tecnología y pensamiento", el cual acoge un conjunto de reflexiones sobre aspectos creativos en relación a la música digital, a la gestación de un estilo artístico como fue el Modernismo musical, a la educación musical y a la notación en la música contemporánea.

Este libro es una aportación relevante al escaso terreno bibliográfico en nuestra lengua referente al desarrollo conceptual que deriva de la relación entre la creatividad musical y la influencia de las modificaciones tecnológicas de la misma. Con los avances tecnológicos que se han producido en los dos últimos siglos y el acceso democratizado a todos ellos, vemos que el concepto de creación musical está inmerso en una metamorfosis constante, pasando de ser un acto intelectual reservado a unos pocos, a ser un proceso dinámico más accesible para todos, basado en la experiencia y en la práctica. Tal y como afirma Berenguer (coautor y director de la orquesta del Caos), deberíamos aspirar a considerar todo proceso creativo como un modelo de ejercicio de libertad, plenamente alcanzable por cualquier ciudadano. En definitiva, conseguir que la creación musical, gracias a la tecnología y a los cambios sociales, sirva como proceso para estimular el espíritu creador y la capacidad crítica y autocrítica de las sociedades.

Salvador Oriola Requena Profesor Asociado. Facultad de Educación, Universidad de Barcelona. 